\title{
Avaliação da qualidade de serviço terceirizado de manutenção em edifício comercial: o caso de uma organização pública
}

\section{Evaluation of quality of outsourced maintenance service in an office building: the case of a public organization}

\author{
Ricardo Lopes Pinto \\ Maria Aparecida Gouvêa ${ }^{2}$ \\ Braulio Oliveira $^{3}$
}

\begin{abstract}
Resumo: O objetivo deste artigo é identificar, no âmbito de uma organização pública, indicadores que possibilitem uma avaliação da qualidade do serviço terceirizado de manutenção de um edifício comercial segundo as perspectivas dos usuários, dos fiscais de contratos de serviços terceirizados e dos responsáveis pelos prestadores de serviços terceirizados. O modelo de Brady e Cronin Junior (2001, p. 37-38) norteou a realização de pesquisas qualitativas para os três segmentos e quantitativa junto aos usuários. Por meio da técnica estatística de modelagem de equações estruturais, obteve-se a definição dos constructos e dos indicadores diretamente relevantes para a aferição da qualidade percebida do serviço.
\end{abstract}

Palavras-chave: Avaliação da qualidade de serviços. Terceirização. Manutenção de facilities. Modelagem em equações estruturais. Partial Least Squares.

\begin{abstract}
The aim of this paper is to identify, in a public organization, indicators to evaluate the quality of the outsourced maintenance services in an office building according to the perspectives of users, service contract inspectors, and those responsible for outsourced service providers. The qualitative and quantitative studies, were carried out with the users for the three segments based on the Brady and Cronin Junior (2001, p. 37-38). Based on the statistical technique of structural equation modeling, the definition of the constructs and indicators relevant to the assessment of perceived service quality was obtained.
\end{abstract}

Keywords: Service quality evaluation. Outsourced services. Facility maintenance. Structural equation modeling. Partial Least Squares.

\section{Introdução}

Interrupções no fornecimento de energia elétrica, inconstância do acesso à rede de computadores ou falhas no funcionamento de sistemas de segurança afetam negativamente o desempenho nas atividades-fim na maioria das organizações (THEN, 2005, p. 33-34). Daí a importância da boa gestão dos serviços relacionados à manutenção predial, de modo que se possa contar com instalações minimamente confiáveis, capazes de conferir satisfatório nível de conforto, funcionalidade e privacidade.

Para tanto, a organização pode optar entre ser ou não a responsável direta pela gestão dos serviços relacionados à manutenção de seus prédios. Não raro, alternativas como contratação de serviços terceirizados ou o emprego de arranjos do tipo Built-to-suit podem se revelar mais vantajosas (MIRSHAWKA, 1991, p. 190-193; KARMAN, 1997, p. 31; REZENDE, 1997, p. 11; BEZERRA; TUBINO, 2000, p. 9; FIGUEIREDO; GRAVA, 2007, p. 11-16).

No caso de grande parte das organizações públicas brasileiras, a terceirização passou a ser utilizada após 1995, em função da Reforma Administrativa que estabeleceu o princípio de que a produção de bens e a prestação de serviços não exclusivos do Estado deveriam ser de atribuição de instituições privadas (BRESSER PEREIRA, 2001, p. 250-253).

\footnotetext{
${ }^{1}$ Escola de Negócios, Universidade Municipal de São Caetano do Sul - USCS, Av. Goiás, 3400, CEP 09550-051, São Caetano do Sul, SP, Brasil, e-mail: ricardoeesc7@ hotmail.com

2 Departamento de Administração, Faculdade de Economia, Administração e Contabilidade - FEA, Universidade de São Paulo - USP, Av. Prof. Luciano Gualberto, 908, Butantã, CEP 05508-010, São Paulo, SP, Brasil, e-mail: magouvea@usp.br

${ }^{3}$ Departamento de Administração, Centro Universitário da FEI, Rua Tamandaré, 688, Liberdade, CEP 01525-000, São Paulo, SP, Brasil, e-mail: braulioliveira@gmail.com
} 
Consequentemente, a regulamentação para compras e contratações públicas teve que ser aprimorada, a bem de resguardar o interesse público, ao prever a necessidade de atendimento a exigências em termos de um patamar mínimo de qualidade e de desempenho estabelecido em edital de convocação (Art. 45 e 46 da Lei 8666/93; Lei 10.520/02) (BRASIL, 1993, 2002).

Neste artigo, a questão da contratação de um serviço com qualidade mínima foi abordada no âmbito de uma organização pública autárquica em que o Relacionamento R6 descrito por Gummesson (2005, p. 44-46) é relevante. Trata-se de uma situação que envolve um consumidor multifacetado e fornecedores multifacetados, ou seja, há relacionamentos entre vários funcionários de cada uma das organizações envolvidas no negócio.

O objetivo principal do estudo foi identificar indicadores que possibilitassem a avaliação da qualidade de um serviço terceirizado de manutenção predial considerando-se as perspectivas dos usuários, dos fiscais de contratos e dos responsáveis pelos prestadores de serviços. Para tanto, foi selecionado o serviço aqui denominado "Serviço de Reparos": reparos em pisos, carpetes e em elementos da rede hidráulica - pias, torneiras e vasos sanitários -, de modo a obter-se respostas para as seguintes questões:

- Quais os aspectos relevantes na avaliação da qualidade do serviço de reparos?

- Qual o grau de qualidade percebida do serviço de reparos?

As respostas foram obtidas a partir dos depoimentos dos usuários, dos fiscais de contratos e dos responsáveis pelos prestadores de serviços, possibilitando a comparação de suas opiniões e a identificação dos aspectos mais valorizados e que requerem ações de melhoria.

\section{Fundamentação teórica}

A questão da durabilidade de edifícios tem alcançado certo destaque dentre os temas discutidos em Construção Civil, uma vez que está diretamente associada ao custo global do bem imóvel. O assunto alcançou importância a ponto de a manutenibilidade ter sido incluída na Norma NBR 15.575 dentre as exigências a serem observadas em termos de projeto de edifícios (ASSOCIAÇÃO..., 2013, p. 71).

Como ressaltam Lindholm e Nenonen (2006, p. 109) e Sapri e Pitt (2005, p. 433-434), a gestão dos bens imobiliários das organizações, incluindo os serviços a eles relacionados, podem ter impacto significativo sobre o negócio essencial da empresa. Lindholm e Nenonen (2006, p. 112-116) inclusive apresentam ferramentas para efetiva mensuração do desempenho em termos de gestão de ativos imobiliários, dentre as quais se inclui a BIU (the Building-In-Use avaliation), técnica especialmente útil para mensuração de algumas das medidas empregadas para avaliação da eficácia e da qualidade da gestão das instalações prediais, como a satisfação dos usuários com as instalações e com os serviços (LINDHOLM; NENONEN, 2006, p. 114). Contudo, tal trabalho não chega ao nível de detalhe de especificar indicadores mensuráveis.

Mais do que mera curiosidade acadêmica, a mensuração da qualidade do serviço de manutenção predial consiste em uma necessidade prática. Szigeti e Davis (2005, p. 24) afirmam que uma importante e recorrente questão levantada pelos gestores de ativos imobiliários refere-se justamente à possibilidade de mensuração da qualidade do serviço de manutenção predial, a fim de verificar se aquilo que se comprou ou alugou vale o preço pago.

Macedo (2005, p. 78) mostra que a avaliação da qualidade do serviço prestado é uma preocupação recorrente nos três modelos de análise de terceirização de serviços de manutenção predial - Modelo CAPS de A.T. Kearney (MONCZKA, 2005), Modelo de Franceschini et al. (2004) e Modelo de Hassanain e Al-Saadi (2005).

Segundo Soares e Scheffler (2005, p. 5), há certa polêmica quanto à relação entre qualidade de serviços e satisfação do consumidor, no que se refere à sua direção causal. Uma corrente afirma que a qualidade de serviços é um antecedente da satisfação do consumidor, enquanto a outra defende que a qualidade é a consequência da satisfação do consumidor. Independente de mérito, tal polêmica evidencia que satisfação do consumidor e qualidade de serviços são constructos que muitos autores consideram conectados entre si.

Servir ao cliente pode ser considerado uma forma eficaz de alcançar a satisfação do consumidor. E fazer isso significa entregar a ele um pacote de benefícios mediante a experiência de utilização do serviço (HOFFMAN, 2001, p. 267). Logo, é no contexto dessa experiência que haverá o julgamento sobre o valor desse pacote de benefícios.

Para desenvolver modelos eficazes de gestão de serviços, é importante compreender o que os clientes procuram e o que eles avaliam (GRÖNROOS, 1995, p. 45). Eis aí algo bastante fácil de enunciar, porém relativamente difícil de operacionalizar: seja porque é consideravelmente complicado compreender o que os clientes procuram exatamente, dada a complexidade do comportamento humano e o caráter dinâmico das necessidades das pessoas; seja porque em muitas situações o cliente não consegue avaliar aspectos importantes do serviço prestado, por exemplo, quando essa avaliação exige conhecimentos técnicos específicos, os quais o cliente não possui, conforme exemplificam Rasila e Gersberg (2007, p. 42). Zeithaml e Bitner (2003, p. 52) e Lovelock e Wright (2001, p. 76) entendem que a dificuldade de avaliação de serviços se dá em um continuum (Figura 1). 
Não obstante haja essa dificuldade, surgiram algumas propostas de mensuração da qualidade de serviços. Dentre as principais, destacam-se as escalas Servqual e Servperf (JAIN; GUPTA, 2004, p. 33).

Parasuraman, Zeithaml e Berry (1988, p. 14-36) desenvolveram a escala Servqual a partir de um modelo de qualidade de serviços elaborado por eles (Figura 2), no qual a percepção do cliente é a referência para a avaliação da qualidade do serviço prestado (PARASURAMAN; ZEITHAML; BERRY, 1985, p. 44-46).

Nessa escala, a qualidade percebida do serviço (Gap 5) é a variável dependente, enquanto os outros quatro gaps são as variáveis independentes (SALOMI;
MIGUEL; ABACKERLI, 2005, p. 281). Cumpre salientar que a variável dependente, qualidade percebida do serviço $(\mathrm{Q})$, é função da diferença entre o desempenho do serviço $(\mathrm{P})$ e a expectativa (E), conforme representado pela expressão $\mathrm{Q}=\mathrm{P}-\mathrm{E}$ (PARASURAMAN; ZEITHAML; BERRY, 1988, p. 19).

Na escala Servqual, a mensuração se dá mediante respostas a 44 itens (22 itens para captar a expectativa quanto a um serviço excelente e 22 itens para avaliar o serviço efetivamente prestado), com temática distribuída em cinco dimensões (Tangibilidade, Confiabilidade, Prontidão, Segurança e Empatia): para cada item, o respondente deve escolher respostas

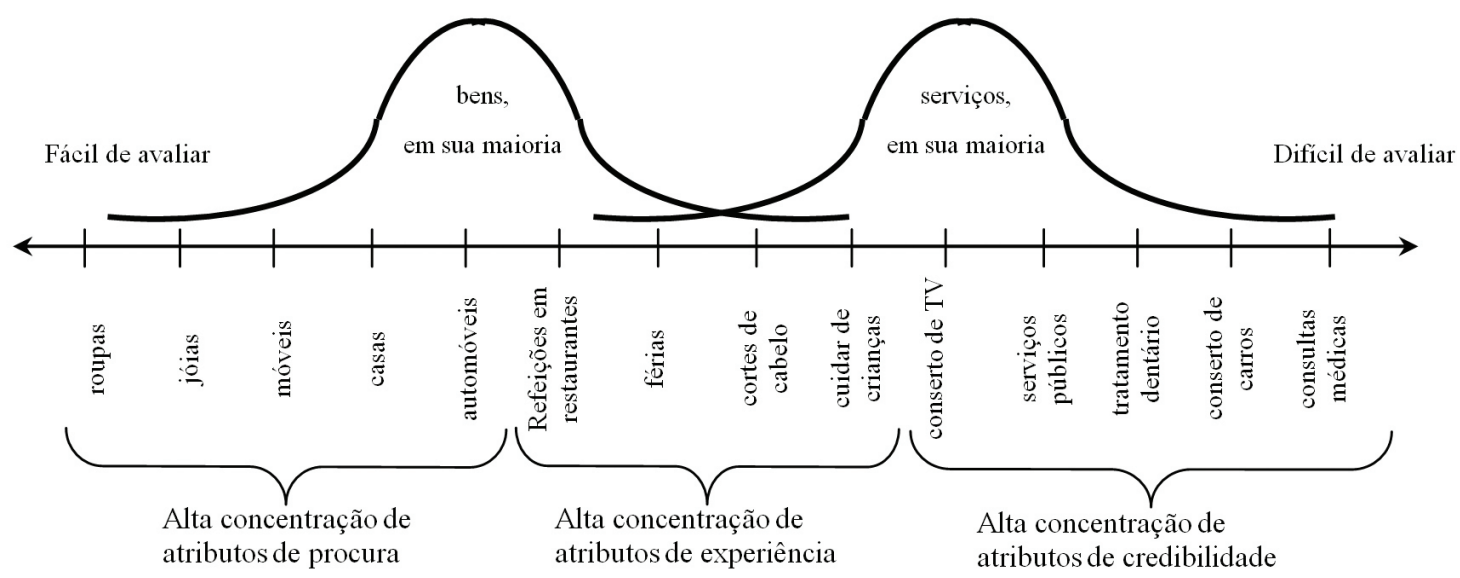

Figura 1. Continuum de avaliação para diferentes tipos de produtos. Fonte: Zeithaml e Bitner (2003, p. 52).

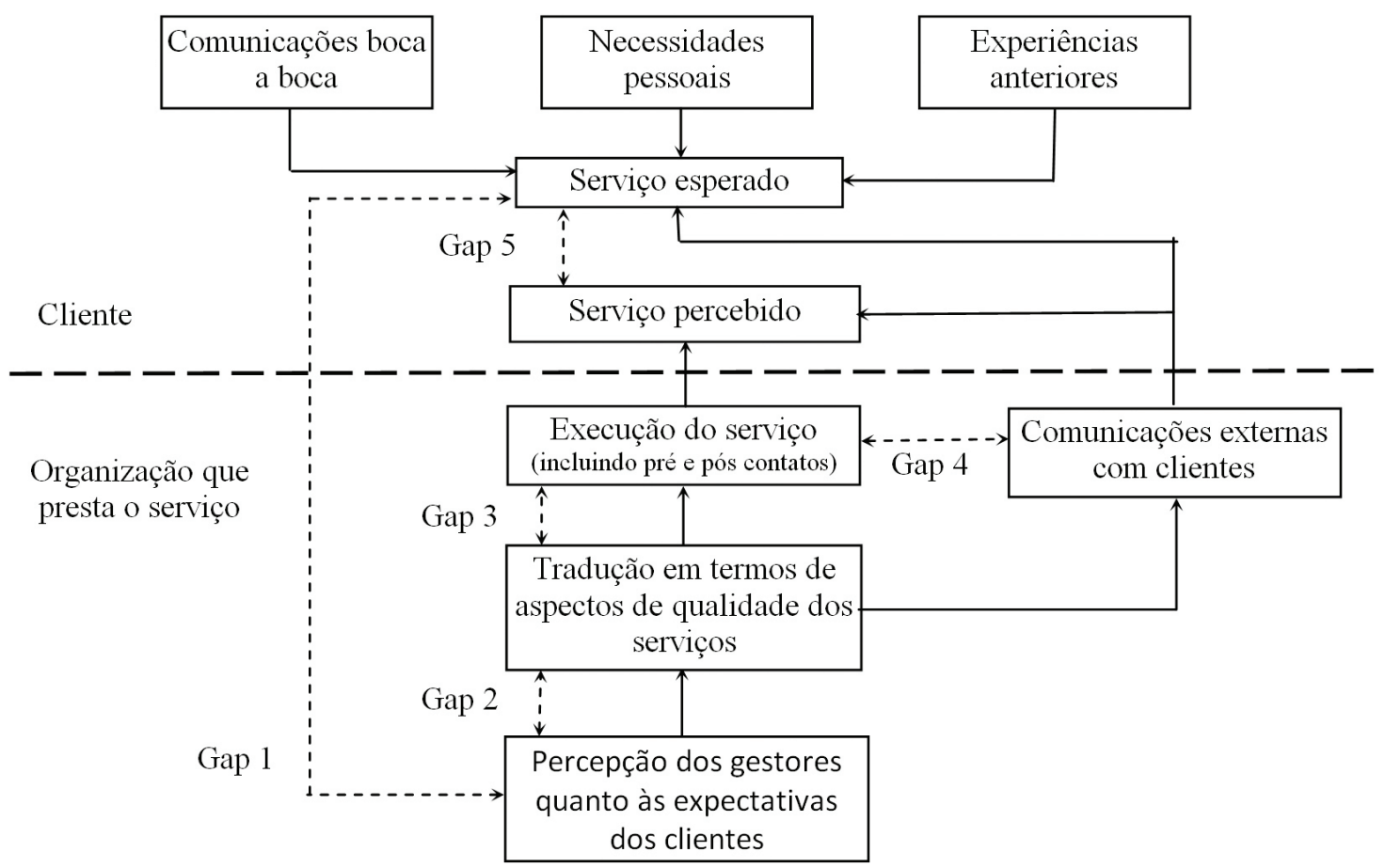

Figura 2. Modelo de qualidade de serviços adotados na Escala SERVQUAL. Fonte: Parasuraman, Zeithaml e Berry (1985, p. 44). 
que variam de "não essencial" a "absolutamente essencial" em escalas do tipo Likert com sete pontos (PARASURAMAN; ZEITHAML; BERRY, 1988, p. 38-40).

Dentre as principais críticas feitas à escala Servqual, destacam-se a falta de praticidade devido à extensão do questionário (JAIN; GUPTA, 2004, p. 27) e as deficiências de mensuração resultantes do emprego do paradigma da desconfirmação (CRONIN JUNIOR; TAYLOR, 1992, p. 58-65; BABAKUS; BOLLER apud FREITAS; BOLSANELLO; VIANA, 2008, p. 91). Apesar das críticas, a Servqual ainda é tida como a mais tradicional ferramenta para a mensuração da qualidade de serviços (HUGHEY et al. apud LOPES; HERNANDEZ; NOHARA, 2009, p. 402).

Outra escala também reconhecida em estudos acadêmicos é a Servperf. A escala Servperf foi proposta por Cronin Junior e Taylor (1992, p. 58-65) a partir de um estudo comparando a sensibilidade em retratar as variações de qualidade de serviços da escala Servqual completa com a de apenas uma parte dela (aquela relativa à avaliação da percepção de desempenho do serviço prestado). O pressuposto empregado é que a qualidade percebida do serviço (Q) é conceituada como uma atitude do cliente, de modo que pode ser apurada mediante uma avaliação do desempenho do serviço $(\mathrm{P})$, consoante a expressão $\mathrm{Q}=\mathrm{P}(\mathrm{SALOMI}$; MIGUEL; ABACKERLI, 2005, p. 283).

O questionário da escala Servperf compreende os mesmos itens aplicados no desenvolvimento do instrumento Servqual (MIGUEL; SALOMI, 2004, p. 24). Isso porque os 22 itens representando as cinco dimensões da qualidade de serviço propostos por Parasuraman, Zeithaml e Berry (1988, p. 39-40) foram considerados bem embasados teoricamente para mensuração da percepção de desempenho do serviço prestado (CRONIN JUNIOR; TAYLOR, 1992, p. 58).

Alguns outros estudos comparando os resultados obtidos por escalas Servqual e Servperf chegaram à conclusão de que a escala Servperf é suficientemente robusta para mensuração da qualidade percebida do serviço (JAIN; GUPTA, 2004, p. 30-35; SALOMI; MIGUEL; ABACKERLI, 2005, p. 287-291; BAYRAKTAROGLU, 2010, p. 57-58).

Um modelo alternativo de mensuração da qualidade de serviços foi proposto por Brady e Cronin Junior (2001, p. 37-38). Estes autores elaboraram um modelo de qualidade de serviços que tem o mérito de decompor a qualidade percebida de um serviço em vários níveis hierárquicos, permitindo uma compreensão mais profunda dos mecanismos que conduzem à qualidade do serviço. Tal modelo incorpora as ideias de Rust e Oliver (1994, p. 1-19) de qualidade de serviço como composição dos constructos ambiente do serviço, entrega do serviço e resultado do serviço; e as de Dabholkar, Thorpe e Rentz (1996, p. 3-16) do modelo de qualidade no qual os constructos se dispõem em níveis. Nesse modelo, a qualidade do serviço é entendida como constructo influenciado por três constructos de segunda ordem (qualidade de interação, qualidade do ambiente físico e qualidade do resultado), cada um deles também influenciado por três constructos de primeira ordem compostos por indicadores de três tipos: confiabilidade, prontidão e empatia (Figura 3).

Numa fase inicial, os autores realizaram um estudo qualitativo e quantitativo, direcionado para oito serviços distintos, com o intuito de identificarem as subdimensões e itens que os consumidores associavam às componentes de ordem superior: Qualidade da Interação, Qualidade do Ambiente Físico e Qualidade

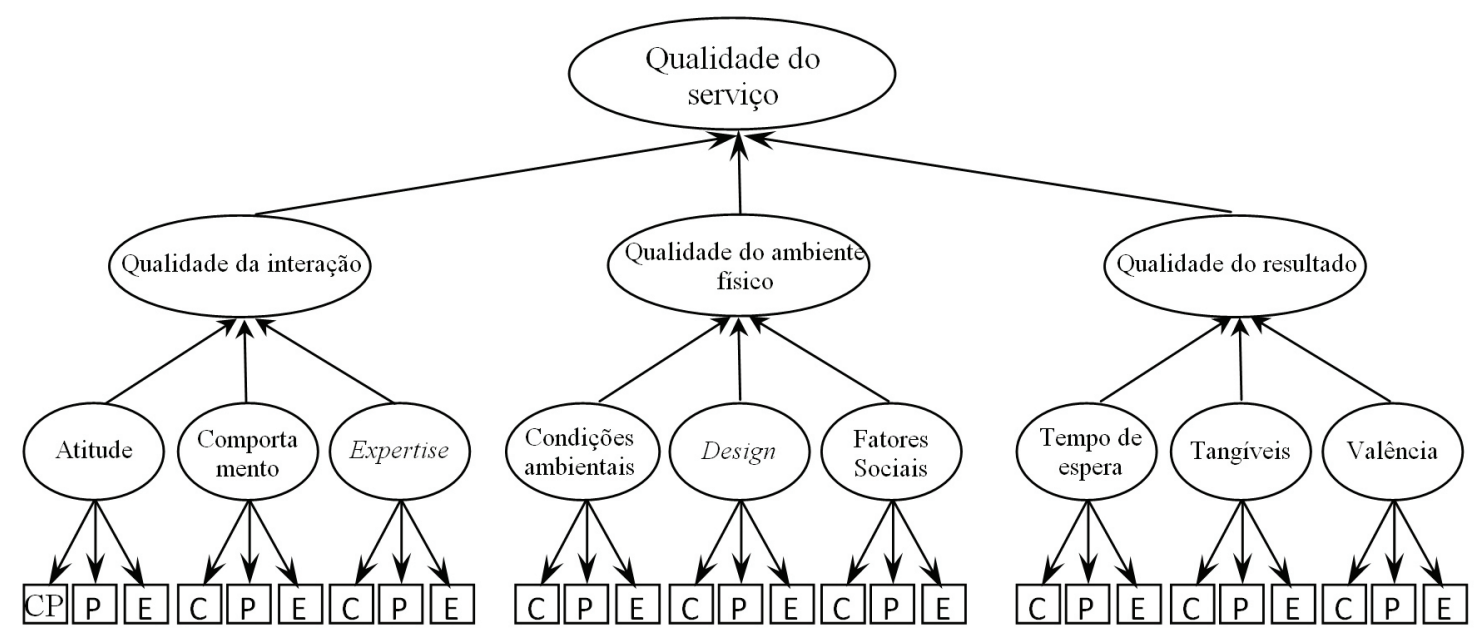

Nota: $\mathrm{C}=$ indicador de confiabilidade; $\mathrm{P}=$ indicador de prontidão e $\mathrm{E}=$ indicador de empatia.

Figura 3. Modelo Hierárquico de Qualidade de Serviços. Fonte: Brady e Cronin Junior (2001, p. 37). 
do Resultado. Aos entrevistados foi pedido que listassem todas as variáveis que influenciavam as suas percepções em cada uma das três componentes referidas, as quais foram alvo de categorização e posterior refinamento.

Determinaram assim nove subdimensões, agregadas em grupos de três e distribuídas pelas três componentes de ordem superior do seguinte modo: as subdimensões Atitude, Comportamento e Expertise foram ligadas à Qualidade da Interação; as subdimensões Condições Ambientais, Design e Fatores Sociais foram associadas à Qualidade do Ambiente Físico; e as subdimensões Tempo de Espera, Elementos Tangíveis e Resultado da Experiência (Valência) foram associadas à Qualidade do Resultado. A aplicação do modelo a oito serviços permitiu corroborar as relações entre os constructos e os indicadores incluídos em cada um deles.

Este estudo teve desdobramentos posteriormente desenvolvidos por outros autores. Caro e García (2008, p. 711-717), Lu, Zhang e Wang (2009, p. 231-236) e Chahal e Kumari (2010, p. 234-244) desenvolveram estudos propondo modelos de mensuração de qualidade de serviços inspirados no modelo de Brady e Cronin Junior (2001, p. 37-38).

\section{Aspectos metodológicos}

Nesse trabalho, o estudo de caso foi escolhido como modo de investigação. Segundo Yin (2005, p. 32), um estudo de caso é

[...] uma investigação empírica que analisa um fenômeno contemporâneo dentro de seu contexto real, quando os limites entre o fenômeno e o contexto não estão claramente definidos [...],

e o pesquisador não possui controle sobre os eventos comportamentais, de forma que a coleta e análise de dados apresentam características específicas.

O problema em questão envolvia um fenômeno contemporâneo (a avaliação informal da qualidade de serviços terceirizados ocorre corriqueiramente, decorrente da experiência com a prestação desses serviços) extremamente relacionado a um contexto (condições particulares da organização em relação à dinâmica do trabalho, à infraestrutura, às necessidades das pessoas), sinalizando ser pertinente a escolha da organização a ser estudada.

A seleção do caso para o estudo se deu de acordo com o Critério da Apropriabilidade dos Dados (MORSE, 1994, p. 230). A escolha do caso foi intencional, procedimento justificável desde que o caso escolhido possua características tais que permitam o estudo adequado do problema de pesquisa. Os fatores considerados suficientes para caracterizar a apropriabilidade dos dados foram os seguintes:

- adequação ao problema de pesquisa (a instituição vivenciava o desafio de encontrar formas de aferir a qualidade dos serviços terceirizados contratados);

- facilidade de acesso aos dados (um dos pesquisadores tinha fácil acesso aos fiscais de contratos, aos usuários e aos prestadores de serviços);

- disposição da instituição de colaborar.

Três populações foram estudadas: usuários, fiscais de contratos e responsáveis pelos prestadores de serviços.

Foi adotada a recomendação de Yin (2005, p. 97) de se empregarem múltiplas fontes de dados e de informações. Foram realizadas pesquisas qualitativas para os três segmentos (com base em focus groups e em entrevistas em profundidade) e quantitativa junto aos usuários (mediante aplicação dos questionários estruturados). O objetivo principal das pesquisas qualitativas foi definir os indicadores para avaliação dos serviços terceirizados de manutenção predial que seriam posteriormente investigados por meio da aplicação de questionários em pesquisas quantitativas.

As pesquisas qualitativas tiveram, por segmento, os seguintes números de entrevistas: usuários: 10; fiscais: 6; prestadores de serviços: 2. Cumpre destacar que nos dois últimos segmentos fez-se um censo.

Quanto à amostragem para a pesquisa quantitativa, ocorreu somente para a população de 773 usuários; para as populações de fiscais de contratos e de responsáveis pelos prestadores de serviços foram feitos censos, pois nenhuma delas possuía mais de 50 elementos, mas apenas 6 e 2, respectivamente.

Dos 260 questionários enviados para usuários, 203 foram recolhidos, sendo 152 considerados úteis, após eliminação de missings e outliers. Todos os questionários enviados para as demais populações foram recolhidos e aproveitados na pesquisa.

O tamanho de amostra dos usuários foi mais do que suficiente para produzir bons resultados no que se refere ao tratamento quantitativo aplicado (técnica de modelagem de equações estruturais com método de estimação baseado em componentes conhecido como PLS - Partial Least Squares), uma vez que foi adotada a recomendação de Marcoulides, Chin e Saunders (2009, p. 174) de calcular o tamanho mínimo da amostra com base na análise do poder do teste estatístico. Cumpre ressaltar que os autores inclusive criticam o uso da Rule of Thumb dos 10 casos por indicador. A análise preliminar do poder (probabilidade de se rejeitar $\mathrm{H}_{0}$ sendo ela falsa) empregando-se o software G*Power versão 3.0.10 (BUCHNER et al., 2008) revelou que o tamanho mínimo de amostra seria de 77 respondentes. Consequentemente, como a amostra empregada (152 questionários) é bastante superior ao tamanho mínimo (77 questionários), foi garantida sensibilidade suficiente para detectar 
como não relevante qualquer aspecto de qualidade realmente insignificante.

\section{Modelo de qualidade de serviços terceirizados de manutenção predial}

O modelo desenvolvido fundamenta-se em uma adaptação do Modelo Hierárquico de Qualidade de Serviços criado por Brady e Cronin Junior (2001, p. 37), complementada pela definição de indicadores no contexto de manutenção de serviços de reparos.

A adaptação consistiu na exclusão de dois constructos: Qualidade do Ambiente Físico e Valência. Optou-se por não incluir Qualidade do Ambiente Físico devido ao reduzido controle dos prestadores de serviços acerca da definição dos aspectos ligados a esse constructo. A manutenção deve ser feita em instalações cujas decisões sobre sua constituição cabem ao cliente, de modo que esse constructo está fora do controle dos responsáveis pela prestação do serviço e, em tese, não influenciaria de modo distinto a avaliação. Já o constructo Valência, que cobre todos os aspectos do resultado do serviço que não se referem nem ao tempo de espera e nem aos aspectos tangíveis, deixou de ser incluído devido à impossibilidade de ser utilizado para fins de melhoria da gestão do serviço, já que os aspectos compreendidos na Valência não são controláveis pelos gestores dos serviços, conforme enfatizam Brady e Cronin Junior (2001, p. 40). A Figura 4 apresenta o modelo adaptado.

Os Quadros 1, 2 e 3 apresentam todos os constructos com seus respectivos indicadores.

Todos os indicadores dos Quadros 1, 2 e 3 foram extraídos de pesquisas qualitativas junto a cada um dos três tipos de respondentes. Ademais, verificou-se que se classificavam em categorias (constructos) com base na literatura pesquisada, de modo que se pode dizer que encontraram respaldo teórico. Cumpre ressaltar que, além disso, foi feito também um pré-teste com o questionário aplicado aos usuários a fim de se verificar a adequação do instrumento de coleta de dados.

Na coleta de dados, solicitou-se que o respondente atribuísse a cada variável uma nota entre zero e 10 contextualizada em termos de uma escala de quatro conceitos: péssimo $(0$ a 2,4$)$; ruim $(2,5$ a 4,9$)$; bom (5,0 a 7,4); e ótimo (7,5 a 10).

Para testar o modelo apresentado na Figura 4, aplicou-se a técnica de modelagem de equações estruturais (MEE ou Structural Equation Modeling - SEM) por meio do software SmartPLS.

Releva notar que o uso de modelagem por equações estruturais combinado a métodos qualitativos é considerado adequado por Jensen et al. (2010, p. 11) para determinar especificamente o valor percebido da gestão dos serviços de manutenção predial, já que possibilita a criação de escalas apropriadas.

O Quadro 4 apresenta as hipóteses testadas pelo modelo.

\section{Análise dos resultados}

Nesta seção, são apresentados os seguintes tópicos: perfil da amostra, modelo de mensuração, modelo estrutural, comparação entre as três categorias de respondentes e avaliação dos indicadores.

\subsection{Perfil da amostra de usuários dos serviços de manutenção de reparos}

A amostra caracteriza-se por: predominantemente masculina, com idade entre 50 e 60 anos, com grau de instrução elevado em relação ao verificado para a população brasileira (praticamente toda a amostra

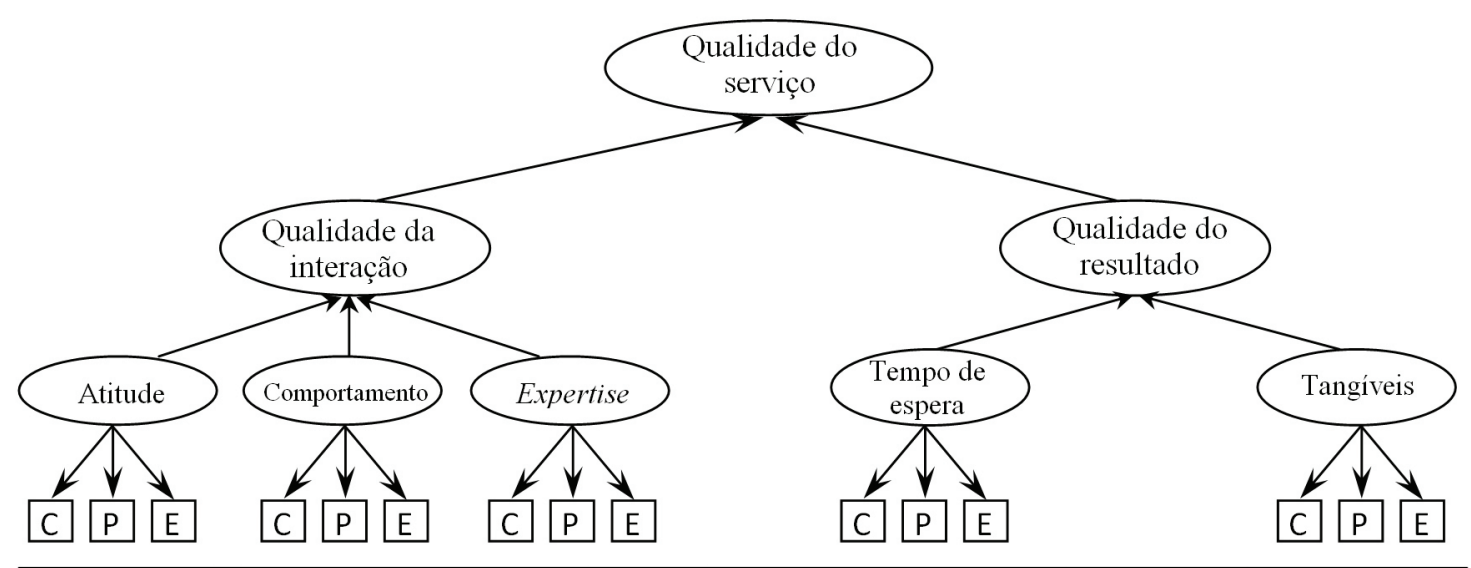

Nota: $\mathrm{C}=$ indicador de confiabilidade; $\mathrm{P}=$ indicador de prontidão e $\mathrm{E}=$ indicador de empatia.

Figura 4. Modelo de Qualidade de Serviços Terceirizados de Manutenção Predial. Fonte: Elaborado pelos autores. 
Quadro 1. Indicadores dos constructos Aspectos Tangíveis e Tempo de Espera.

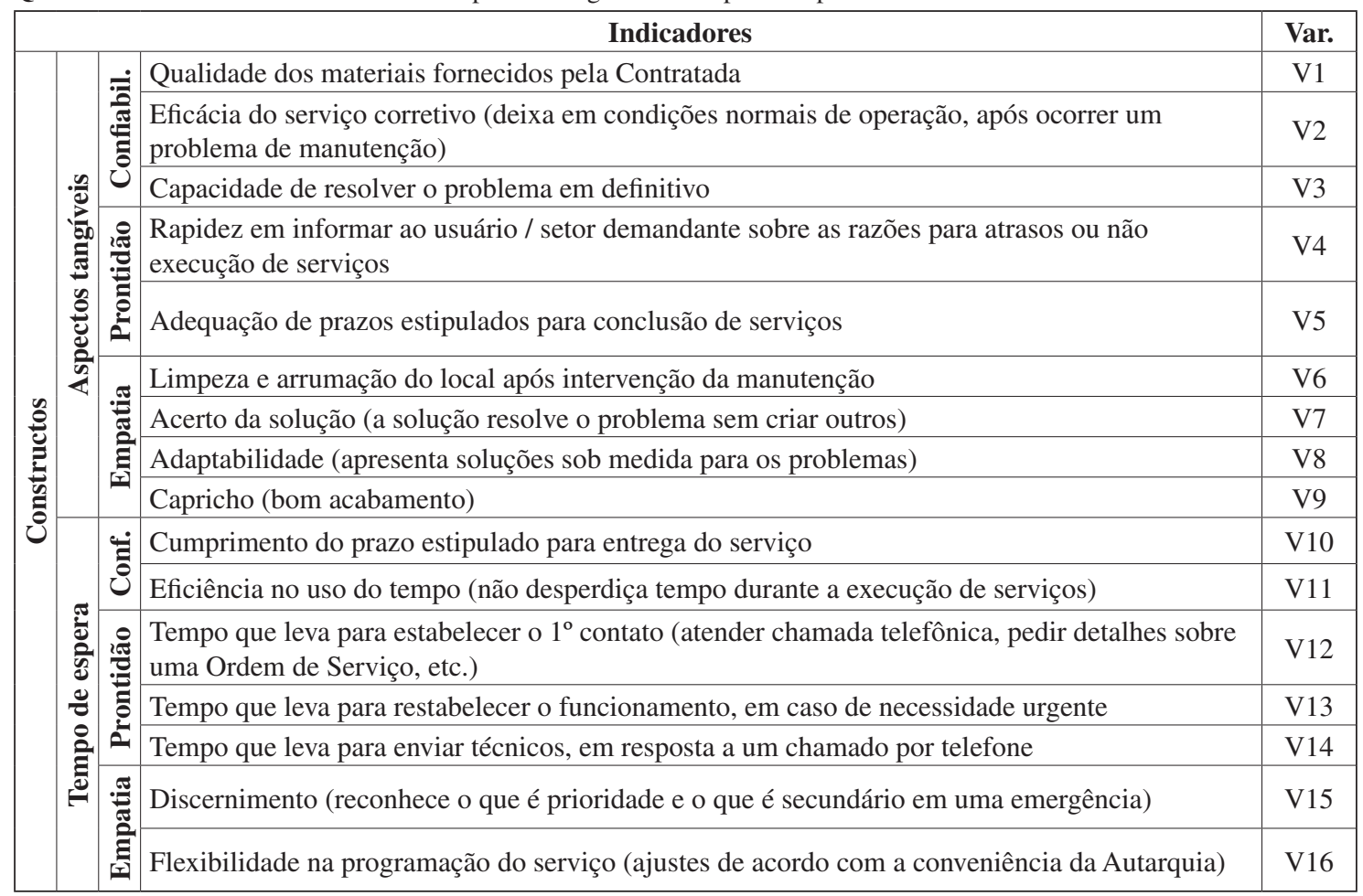

Fonte: Elaborado pelos autores.

Quadro 2. Indicadores dos constructos Atitude e Comportamento.

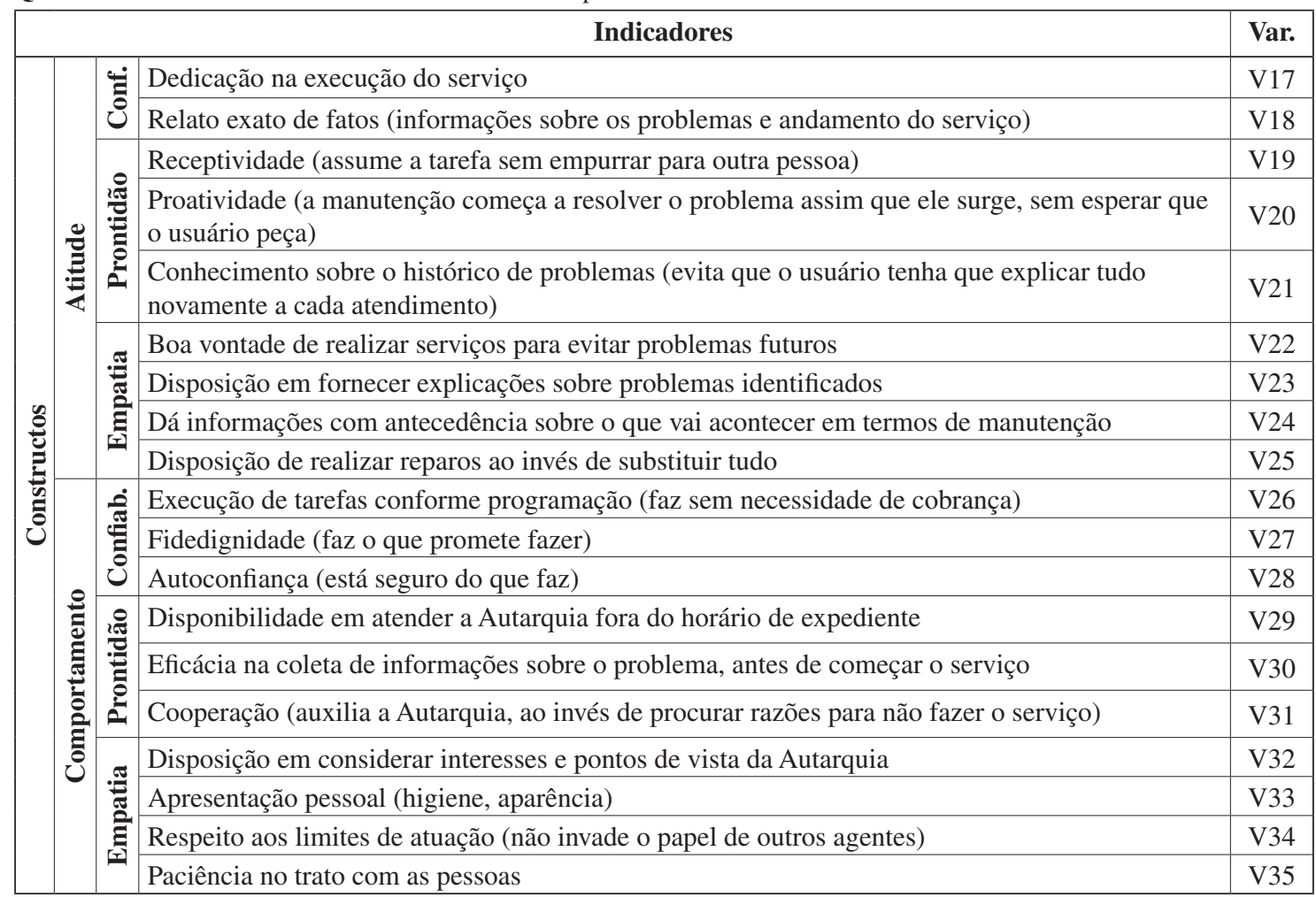

Fonte: Elaborado pelos autores. 
Quadro 3. Indicadores dos constructos Expertise, Qualidade de Interação, Qual. do Resultado e Qual. Serviço.

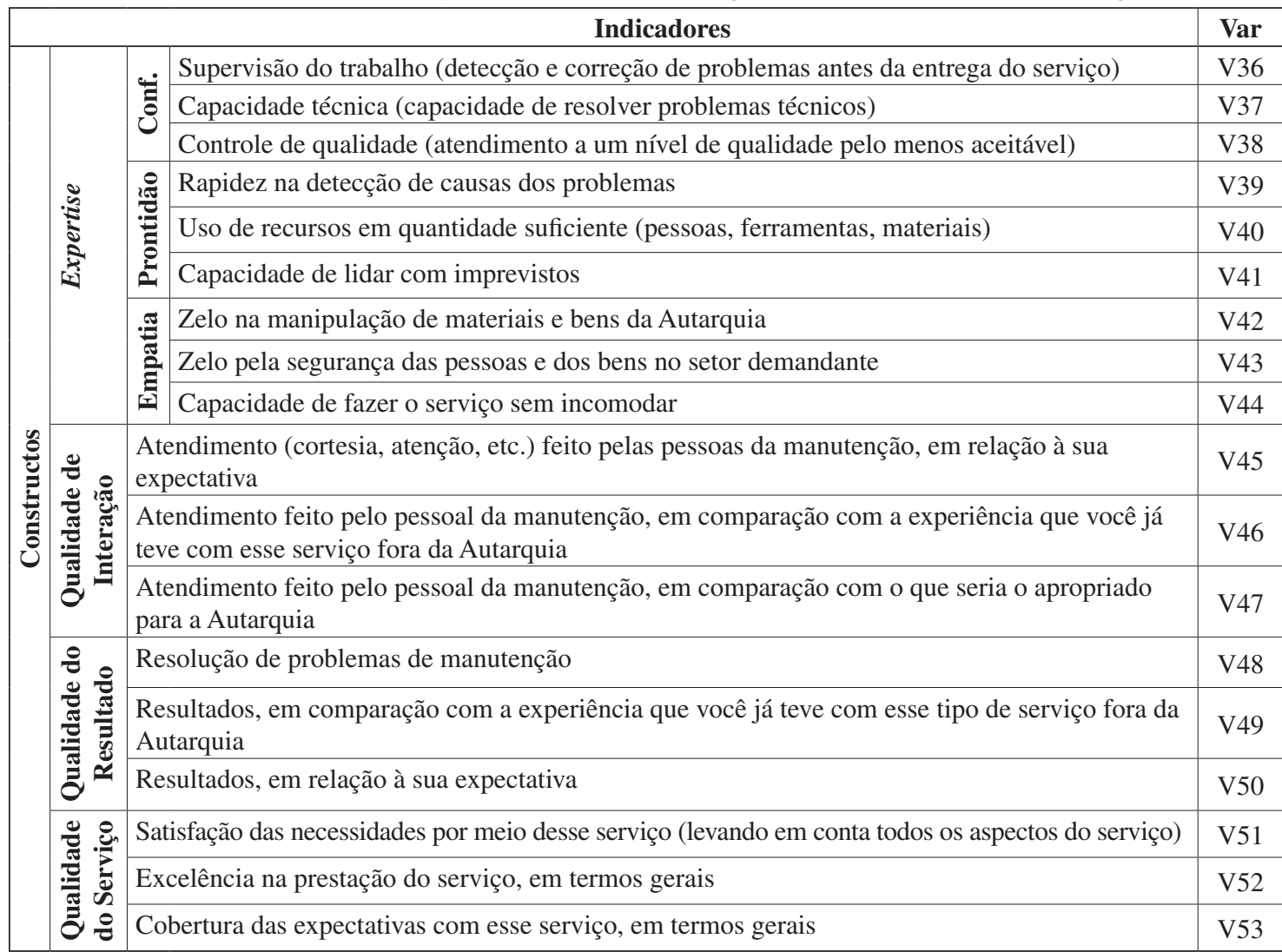

Fonte: Elaborado pelos autores.

Quadro 4. Resumo das hipóteses.

\begin{tabular}{|l|l|}
\hline \multicolumn{2}{|c|}{ Hipótese } \\
\hline $\mathrm{H}_{1}$ & A percepção sobre a qualidade de interação contribui diretamente para a percepção da qualidade do serviço. \\
\hline $\mathrm{H}_{2}$ & $\begin{array}{l}\text { A percepção sobre as atitudes dos funcionários das empresas terceirizadas influencia diretamente a } \\
\text { percepção da qualidade de interação. }\end{array}$ \\
\hline $\mathrm{H}_{3}$ & $\begin{array}{l}\text { A percepção sobre o comportamento dos funcionários das empresas terceirizadas influencia diretamente a } \\
\text { percepção da qualidade de interação. }\end{array}$ \\
\hline $\mathrm{H}_{4}$ & $\begin{array}{l}\text { A percepção sobre a expertise dos funcionários das empresas terceirizadas influencia diretamente a } \\
\text { percepção da qualidade de interação. }\end{array}$ \\
\hline $\mathrm{H}_{5}$ & A percepção sobre a qualidade do resultado contribui diretamente para a percepção da qualidade do serviço. \\
\hline $\mathrm{H}_{6}$ & A percepção sobre o tempo de espera influencia diretamente a percepção da qualidade do resultado. \\
\hline $\mathrm{H}_{7}$ & $\begin{array}{l}\text { A percepção sobre os aspectos tangíveis do serviço influencia diretamente a percepção da qualidade do } \\
\text { resultado. }\end{array}$ \\
\hline
\end{tabular}

Fonte: Elaborado pelos autores.

é composta de pessoas que cursaram pelo menos o ensino superior), com predomínio de ocupantes do cargo de Analista e desempenhando funções em alguma das áreas consideradas atividades-fim da instituição.

A distribuição das variáveis sexo, idade, escolaridade e cargo traduziu com boa aproximação a situação da população dos usuários de serviços de reparos que são os funcionários da organização pesquisada.

\subsection{Modelo de mensuração}

A etapa de avaliação do modelo de mensuração consiste na verificação da adequação dos conceitos inseridos em cada um dos oito constructos do modelo apresentados nos Quadros 1, 2 e 3.

Hair Junior et al. (2005, p. 126) recomendam a análise das validades convergente e discriminante:

- Validade convergente: avalia o grau em que duas medidas do mesmo conceito estão correlacionadas; 
- Validade discriminante: consiste no grau em que dois conceitos são distintos.

A estatística Average Variance Extracted (AVE) permite medir o grau de validade:

- Convergente: existente caso os valores da variância média extraída (Average Variance Extracted, AVE) dos constructos, que representa a sua relação com seus indicadores, sejam iguais ou superiores a 0,5 (ZWICKER; SOUZA; BIDO, 2008, p. 7). Cargas altas, 0,7 ou superiores, das variáveis em seus respectivos constructos também indicam validade convergente (BIDO et al., 2008).

- Discriminante: avaliada pela comparação das correlações entre os constructos com o valor da raiz quadrada da AVE daquele constructo e/ou pelo exame das cargas cruzadas entre os constructos e suas variáveis componentes (ZWICKER; SOUZA; BIDO, 2008, p. 7-8).

Conforme essas regras, houve necessidade de remoção das variáveis V17, V25, V26 e V34. Os demais indicadores apresentaram cargas superiores a 0,7. Assim, houve pertinência na definição dos indicadores para cada um dos oito constructos do modelo deste estudo.

\subsection{Modelo estrutural}

A avaliação do modelo estrutural corresponde à análise da relação entre os constructos, que permite testar as hipóteses exibidas no Quadro 4.

Primeiramente avaliam-se os coeficientes estruturais referentes às relações entre pares de constructos. Depois da obtenção do modelo final com a manutenção de todos os coeficientes estruturais significantes, passa-se à análise das medidas gerais de qualidade de ajuste do modelo.

Algumas medidas de qualidade do modelo utilizadas neste estudo, segundo definições de Zwicker, Souza e Bido (2008, p. 5):

- $\mathrm{R}^{2}$ : variância explicada; grau em que as variáveis dependentes são previstas pelas independentes.
- Goodness-of-fit (GoF): índice de adequação que mede quanto da variância é explicada pelo modelo, proposto por Tenenhaus et al. (2005 apud ZWICKER; SOUZA; BIDO, 2008, p. 5). Calculado pela média geométrica entre o $\mathrm{R}^{2}$ médio (adequação do modelo estrutural) e a AVE média (adequação do modelo de mensuração).

A primeira etapa de análise revelou que o modelo proposto estava inadequado do ponto de vista estrutural, já que o coeficiente estrutural do constructo Comportamento, que o conecta ao constructo Qualidade de interação, tinha grande probabilidade de assumir valor zero (Quadro 5).

Sendo assim, uma nova modelagem foi testada (empregaram-se todas as variáveis da modelagem anterior, exceto a variável latente Comportamento e as variáveis mensuráveis que funcionavam como seus indicadores). Essa última modelagem ajustou-se muito bem aos dados: a avaliação do modelo de mensuração revelou que as relações entre os indicadores e as variáveis latentes (constructos) são suficientemente robustas, enquanto a avaliação do modelo estrutural apontou elevados indicadores de ajuste geral (Quadro 6).

A Figura 5 mostra a modelagem em sua forma final e explicita os valores dos coeficientes estruturais obtidos.

Uma vez revelado o modelo adequado para o serviço em questão, foi possível enfim dimensionar a importância de cada elemento conceitual para composição da qualidade do serviço. O Quadro 7 apresenta as hipóteses confirmadas pelo modelo e as variáveis empregadas em sua composição.

O Quadro 8 e o Quadro 9 apresentam as contribuições de cada constructo para a explicação das variâncias dos constructos endógenos (Qualidade de interação, Qualidade do resultado e Qualidade do serviço), as quais foram calculadas com base na exposição de Bido et al. (2008, p. 14), ou seja, como produto do valor do coeficiente estrutural que liga os dois constructos com o valor da correlação entre esses constructos.

O constructo Qualidade do resultado desempenha o papel principal para definição da qualidade do serviço

Quadro 5. Valores de t para os coeficientes estruturais.

\begin{tabular}{|c|c|c|}
\hline Coeficiente estrutural & $\mathbf{t}$ & Sig. \\
\hline Qualidade de interação $\times$ Qualidade de serviço & 3,443 & 0,001 \\
\hline Atitude $\times$ Qualidade de interação & 4,031 & 0,000 \\
\hline Comportamento $\times$ Qualidade de interação & 1,171 & 0,242 \\
\hline Expertise $\times$ Qualidade de interação & 5,738 & 0,000 \\
\hline Qualidade do resultado $\times$ Qualidade do serviço & 10,462 & 0,000 \\
\hline Tempo de espera $\times$ Qualidade do resultado & 4,402 & 0,000 \\
\hline Aspectos tangíveis $\times$ Qualidade do resultado & 6,308 & 0,000 \\
\hline
\end{tabular}

Fonte: Elaborado pelos autores. 
Quadro 6. Avaliação do modelo estrutural.

\begin{tabular}{|l|l|}
\hline $\begin{array}{l}\text { Estimativas para os valores dos } \\
\text { coeficientes estruturais }\end{array}$ & $\begin{array}{l}\text { Todos os coeficientes estruturais são diferentes de zero (com nível de } \\
\text { significância estatística inferior a 0,05). }\end{array}$ \\
\hline \multirow{2}{*}{$\mathrm{R}^{2}$} & $\begin{array}{l}\mathrm{R}^{2} \text { de Qualidade de Serviço }=0,888 \text { (substancial) } \\
\mathrm{R}^{2} \text { de Qualidade de Interação }=0,852 \text { (substancial) } \\
\mathrm{R}^{2} \text { de Qualidade de Resultado }=0,778 \text { (substancial) }\end{array}$ \\
\hline Goodness-of-fit $(\mathrm{GoF})$ & $\mathrm{GoF}=0,822472$ (Valor superior a 0,5, considerado mínimo aceitável) \\
\hline
\end{tabular}

Fonte: Elaborado pelos autores.

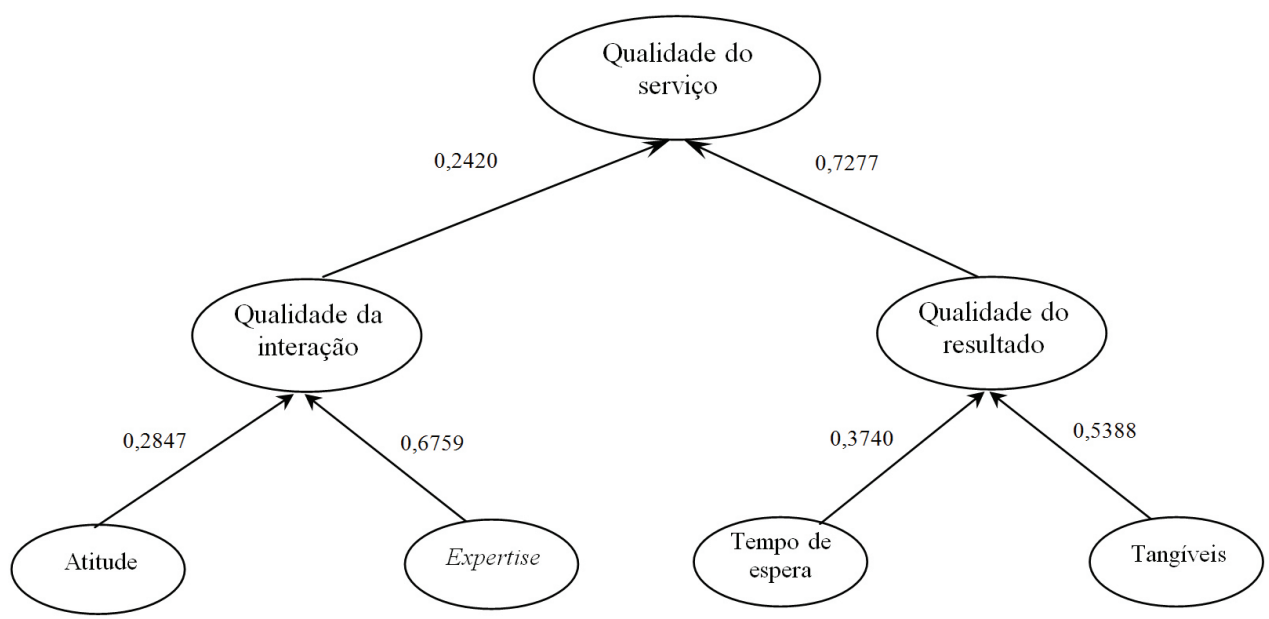

Figura 5. Modelo válido para o serviço "Reparos”. Fonte: Elaborado pelos autores.

Quadro 7. Hipóteses confirmadas e variáveis; das 7 hipóteses, apenas a hipótese $\mathrm{H}_{3}$ não foi confirmada.

\begin{tabular}{|c|l|l|}
\hline \multicolumn{1}{|c|}{ Hipótese } & \multicolumn{1}{|c|}{ Variáveis } \\
\hline $\mathrm{H}_{1}$ & $\begin{array}{l}\text { A percepção sobre a qualidade de interação contribui } \\
\text { diretamente para a percepção da qualidade do serviço. }\end{array}$ & $\begin{array}{l}\text { Qualidade da interação (V45 a V47) e } \\
\text { Qualidade do serviço (V51 a V53). }\end{array}$ \\
\hline $\mathrm{H}_{2}$ & $\begin{array}{l}\text { A percepção sobre as atitudes dos funcionários das empresas } \\
\text { terceirizadas influencia diretamente a percepção da qualidade } \\
\text { de interação. }\end{array}$ & $\begin{array}{l}\text { Atitude (V17 a V25) e Qualidade da } \\
\text { interação (V45 a V47). }\end{array}$ \\
\hline $\mathrm{H}_{4}$ & $\begin{array}{l}\text { A percepção sobre a expertise dos funcionários das empresas } \\
\text { terceirizadas influencia diretamente a percepção da qualidade } \\
\text { de interação. }\end{array}$ & $\begin{array}{l}\text { Expertise (V36 a V44) e Qualidade da } \\
\text { interação (V45 a V47). }\end{array}$ \\
\hline $\mathrm{H}_{5}$ & $\begin{array}{l}\text { A percepção sobre a qualidade do resultado contribui } \\
\text { diretamente para a percepção da qualidade do serviço. }\end{array}$ & $\begin{array}{l}\text { Qualidade do resultado (V48 a V50) e } \\
\text { Qualidade do serviço (V51 a V53). }\end{array}$ \\
\hline $\mathrm{H}_{6}$ & $\begin{array}{l}\text { A percepção sobre o tempo de espera influencia diretamente a } \\
\text { percepção da qualidade do resultado. }\end{array}$ & $\begin{array}{l}\text { Tempo de espera (V10 a V16) e Qualidade } \\
\text { do resultado (V48 a V50). }\end{array}$ \\
\hline $\mathrm{H}_{7}$ & $\begin{array}{l}\text { A percepção sobre os aspectos tangíveis do serviço influencia } \\
\text { diretamente a percepção da qualidade do resultado. }\end{array}$ & $\begin{array}{l}\text { Aspectos tangíveis (V1 a V9) e Qualidade do } \\
\text { resultado (V48 a V50). }\end{array}$ \\
\hline
\end{tabular}

Fonte: Elaborado pelos autores.

de Reparos, já que explica 67,97\% da variância da Qualidade do serviço $(0,6797 \times 100)$, enquanto o constructo Qualidade de interação explica 20,87\% $(0,2087 \times 100)$.

Quanto à contribuição dos constructos exógenos Aspectos tangíveis e Tempo de espera para a explicação da variância do constructo Qualidade do resultado (Quadro 9), cumpre destacar um certo equilíbrio, com ligeira vantagem do valor da contribuição do constructo Aspectos tangíveis ( 0,4644 versus 0,3140$)$. Já no que se refere à contribuição dos constructos exógenos Atitude e Expertise para a explicação da variância do constructo Qualidade de interação (Quadro 9), nota-se uma maior importância do constructo Expertise (0,6139 versus 0,2380).

\subsection{Comparação entre as três categorias de respondentes}

Os resultados da modelagem em equações estruturais viabilizaram a hierarquização dos constructos em termos de importância relativa (Quadro 10): 
Quadro 8. Contribuição de cada constructo para explicação da variância da Qualidade do serviço.

\begin{tabular}{|c|c|c|c|}
\hline Constructos & $\begin{array}{c}\text { Coeficiente estrutural do } \\
\text { constructo com Qualidade } \\
\text { do serviço }\end{array}$ & $\begin{array}{l}\text { Correlação do constructo } \\
\text { com Qualidade do serviço }\end{array}$ & $\begin{array}{c}\text { Contribuição para a variação da } \\
\text { Qualidade do serviço }\end{array}$ \\
\hline Qualidade de interação & 0,242 & 0,8624 & 0,2087 \\
\hline Qualidade do resultado & 0,7277 & 0,934 & 0,6797 \\
\hline & \multicolumn{2}{|c|}{$\mathrm{R}^{2}$ Qualidade do serviço $=0,888$} & Soma $=0,8884$ \\
\hline
\end{tabular}

Fonte: Elaborado pelos autores.

Quadro 9. Contribuição de cada constructo para explicação da variância dos constructos endógenos.

\begin{tabular}{|c|c|c|c|}
\hline Constructos & $\begin{array}{c}\text { Coeficiente estrutural do } \\
\text { constructo com Qualidade do } \\
\text { resultado }\end{array}$ & $\begin{array}{l}\text { Correlação do constructo com } \\
\text { Qualidade do resultado }\end{array}$ & $\begin{array}{c}\text { Contribuição para a variação } \\
\text { da Qualidade do resultado }\end{array}$ \\
\hline Aspectos tangíveis & 0,5388 & 0,8619 & 0,4644 \\
\hline \multirow[t]{3}{*}{ Tempo de espera } & 0,3740 & 0,8395 & 0,3140 \\
\hline & \multicolumn{2}{|c|}{$\mathrm{R}^{2}$ Qualidade do resultado $=0,778$} & Soma $=0,7784$ \\
\hline & $\begin{array}{l}\text { Coeficiente estrutural do } \\
\text { constructo com Qualidade de } \\
\text { interação }\end{array}$ & $\begin{array}{l}\text { Correlação do constructo com } \\
\text { Qualidade de interação }\end{array}$ & $\begin{array}{c}\text { Contribuição para a variação } \\
\text { da Qualidade de interação }\end{array}$ \\
\hline Atitude & 0,2847 & 0,8361 & 0,2380 \\
\hline \multirow[t]{2}{*}{ Expertise } & 0,6759 & 0,9082 & 0,6139 \\
\hline & \multicolumn{2}{|c|}{$\mathrm{R}^{2}$ Qualidade da interação $=0,852$} & Soma $=0,8519$ \\
\hline
\end{tabular}

Fonte: Elaborado pelos autores.

Quadro 10. Importância relativa dos constructos.

\begin{tabular}{|l|c|c|}
\hline \multicolumn{1}{|c|}{ Constructos } & Contribuição para a explicação da variância da Qualidade do serviço & $\begin{array}{c}\text { Importância } \\
\text { relativa }\end{array}$ \\
\hline Qualidade de interação & 0,2087 & 2 \\
\hline Qualidade do resultado & 0,6797 & 1 \\
\hline & Contribuição para a explicação da variância da Qualidade do resultado & 1 \\
\hline Aspectos tangíveis & 0,4644 & 2 \\
\hline Tempo de espera & 0,3140 & 2 \\
\hline & Contribuição para a explicação da variância da Qualidade de interação & \\
\hline Atitude & 0,2380 & 1 \\
\hline Expertise & 0,6139 & 2 \\
\hline
\end{tabular}

Fonte: Elaborado pelos autores.

A partir dessa hierarquização, se tornou possível fazer uma comparação com as hierarquizações feitas pelas outras duas categorias de respondentes na etapa de realização de pesquisa qualitativa. A Figura 6 permite a visualização conjunta das respostas das três categorias de respondentes, de modo a favorecer a comparação sobre a importância relativa dada a cada constructo.

Cabe notar que as três categorias de respondentes foram unânimes em apontar o constructo Qualidade do resultado como mais importante do que o constructo Qualidade de interação.

Porém, quanto à importância dos constructos exógenos Aspectos tangíveis e Tempo de espera, foi observada a discordância dos responsáveis pelos prestadores dos serviços em relação à concordância entre os fiscais de contratos e usuários, o que pode indicar uma percepção equivocada dos responsáveis pelos prestadores dos serviços acerca dos aspectos valorizados por seus clientes.

Quanto à importância dos constructos exógenos Expertise e Atitude, verificou-se que entre os fiscais de contratos e usuários houve concordância de que o constructo Expertise tem a primazia em relação ao constructo Atitude. No entanto, os responsáveis pelos prestadores dos serviços mais uma vez indicaram uma priorização inversa, o que reforça a suspeita sobre uma percepção equivocada da parte deles acerca dos aspectos valorizados por seus clientes.

No que se refere ao constructo Comportamento (excluído da modelagem), cabe destacar que este 


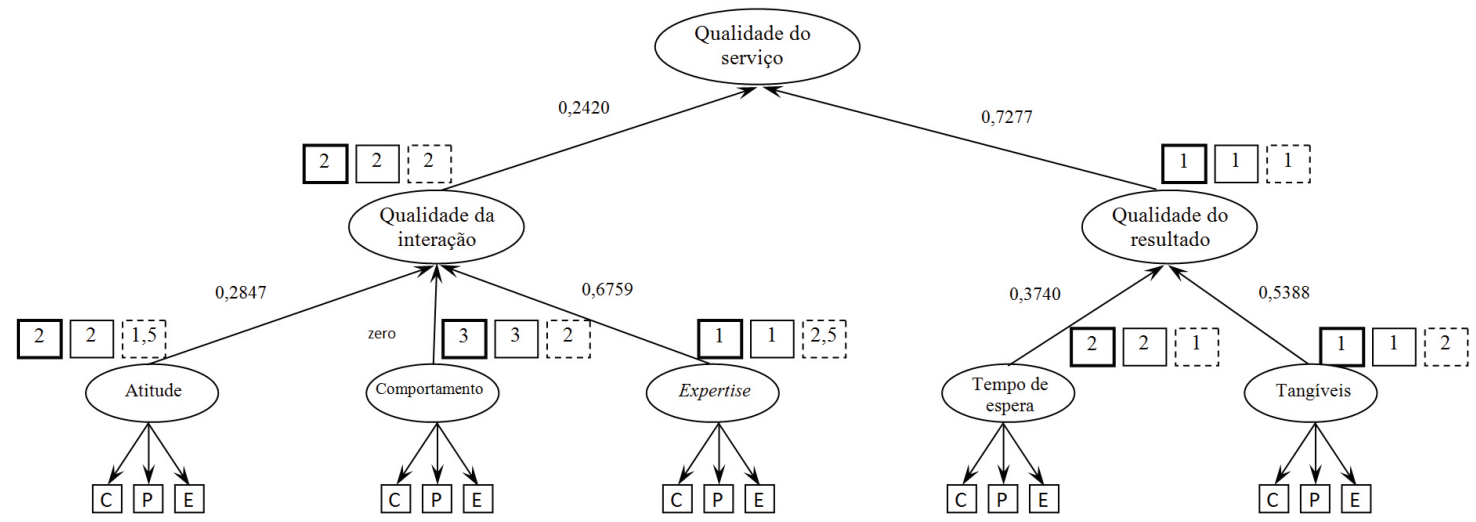

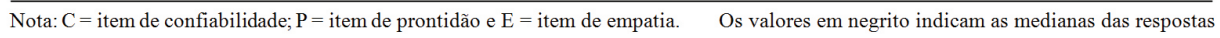

\begin{tabular}{|c|}
\hline Respostas dos usuários \\
valores obtidos a partir da \\
ordenação dos valores dos \\
coeficientes estruturais
\end{tabular}

Respostas dos fiscais de
contratos
ordenação dos constructos

pespostas dos responsáveis

Figura 6. Hierarquização da importância relativa dos constructos para cada categoria de respondentes. Fonte: Elaborado pelos autores.

foi apontado pelos usuários e fiscais como o menos importante dentre os três constructos.

\subsection{Avaliação dos indicadores}

Além da investigação acerca da importância dos constructos, cabe conhecer a avaliação de cada indicador por categoria de respondentes, a fim de examinar se há ou não alguma diferença na forma de julgar a qualidade desse serviço em função do papel desempenhado pelo respondente (usuário, fiscal de contrato ou responsável pelos prestadores de serviços). Foi realizado, para cada indicador, o teste não paramétrico de igualdade de médias de Kruskal-Wallis, recomendado quando se comparam as médias de três grupos de respondentes.

Uma análise conjunta dos resultados permite concluir que, no geral, não há diferença entre a avaliação feita para esse serviço por usuários, fiscais de contrato e responsáveis pelos prestadores de serviços. A exceção fica por conta de apenas três indicadores: Flexibilidade na programação do serviço (V16), Disponibilidade em atender o Banco fora do horário de expediente (V29) e Cooperação (V31), os quais recebem médias mais altas por parte dos fiscais e mais baixas provenientes das opiniões dos usuários.

Um exame dos valores das médias atribuídas às variáveis permite concluir que, de modo geral, este é considerado um bom serviço, já que a média da grande maioria das variáveis situa-se dentro do intervalo de valores que traduzem o conceito de boa avaliação (valores de 5,0 a 7,4).

\section{Conclusões}

Este estudo foi realizado com o propósito de identificar, no âmbito de uma organização pública autárquica, indicadores que possibilitassem uma avaliação da qualidade do serviço terceirizado de manutenção considerando-se as perspectivas dos usuários, dos fiscais de contratos e dos responsáveis pelos prestadores de serviços. Dentro das limitações inerentes à opção metodológica adotada, o objetivo foi alcançado, uma vez que foram obtidas respostas para as questões colocadas.

A primeira delas, referente à identificação dos aspectos relevantes na avaliação da qualidade do serviço de reparos, obteve resposta na medida em que o trabalho arrolou os aspectos que influenciam a qualidade percebida dos serviços de manutenção de reparos, segundo os três estratos de interesse (usuários, fiscais e prestadores de serviços). Os Quadros 1, 2 e 3 apresentam os 41 indicadores (denominados como variáveis no estudo) úteis para a avaliação da qualidade do "Serviço de Reparos", observada a exclusão de 12 variáveis (V17, V25, V26, V27, V28, V29, V30, V31, V32, V33, V34 e V35). Cumpre salientar que a exclusão dessas variáveis, motivada pela avaliação do modelo de mensuração e do modelo estrutural no processamento dos dados referentes aos usuários, faz sentido. Via de regra, para usuários é muito difícil avaliar indicadores como "Dedicação na execução do serviço" (V17), "Disposição de realizar reparos ao invés de substituir tudo" (V25) ou quaisquer das variáveis que compõem o constructo "Comportamento" (V26 a V35), uma vez que se referem a aspectos mais perceptíveis apenas para quem acompanha bem de 
perto a execução do serviço. Aliás, esses indicadores foram sugeridos por fiscais e prestadores de serviços na fase da pesquisa qualitativa.

Consequentemente, a implicação prática imediata, no âmbito da organização pública pesquisada, é que os 41 indicadores validados poderão servir para operacionalizar a avaliação periódica da qualidade do serviço "Reparos", mediante emprego de instrumentos de coleta de dados criados com base nos resultados desta pesquisa.

Em termos de contribuição teórica para aprimoramento do conhecimento no tema "Avaliação da Qualidade de Serviços", destaca-se a confirmação da validade do encadeamento dos constructos "Qualidade do Serviço", "Qualidade do Resultado" e "Qualidade de Interação" proposta no Modelo de Brady e Cronin Junior (2001, p. 37-38). A partir dos dados obtidos dos usuários, verificou-se que o constructo "Qualidade do Serviço" é definido pelos constructos "Qualidade do Resultado" (responsável por 67,97\% da variância da Qualidade do Serviço) e "Qualidade de Interação" (que explica 20,87\% da variância da Qualidade do Serviço). Também foi confirmada a validade do encadeamento dos constructos "Qualidade do Resultado" com os constructos "Tempo de Espera" e "Aspectos Tangíveis", bem como do constructo "Qualidade de Interação" com os constructos "Expertise" e "Atitude" - vide as hipóteses confirmadas (Quadro 7).

Outro resultado que merece destaque é a obtenção da importância relativa de cada constructo de mesmo nível (Figura 6). Foi verificada a convergência de opinião de todos no que se refere à maior importância relativa do constructo "Qualidade do Resultado" em relação ao constructo "Qualidade de Interação"; contudo, no que se refere aos demais constructos, houve convergência apenas entre as indicações dos usuários e dos fiscais de contratos. Nenhuma das opiniões dos responsáveis pelos prestadores de serviços sobre a importância relativa desses constructos coincidiu com a dos usuários e fiscais de contratos. Tal resultado pode sugerir que os fiscais de contrato conseguem captar satisfatoriamente as expectativas dos usuários e que pode haver alguma dificuldade dos responsáveis pelos prestadores de serviços em identificar os elementos mais relevantes para execução do serviço na visão dos usuários e dos fiscais de contratos.

Já a segunda questão, referente ao grau de qualidade percebida do serviço de reparos, obteve resposta em função da apuração das notas atribuídas pelos respondentes. O estudo revelou que o serviço foi considerado bom pelas três categorias de respondentes. Releva notar que, no geral, não foi detectada diferença significativa na avaliação de usuários, fiscais de contratos e responsáveis pelos prestadores de serviços quanto às notas atribuídas para a qualidade do serviço (os testes de igualdade de médias feitos para cada indicador revelaram que apenas para três dos 53 indicadores avaliados houve diferença significativa entre as notas atribuídas). Ademais, a média da nota atribuída para a grande maioria das variáveis situa-se dentro do intervalo de valores que traduzem o conceito de boa avaliação (valores de 5,0 a 7,4). Portanto, pode-se supor que a atuação dos fiscais de contratos na cobrança de resultados da empresa prestadora de serviço tem sido satisfatória, bem como a atuação dos responsáveis pelos prestadores de serviços, que tem sido suficientemente aceitável.

Uma vez que se trata de um estudo exploratório, cabe ressaltar que eventual generalização da validade do modelo teórico empregado (adaptado do Modelo de Brady e Cronin Junior (2001, p. 37-38)) só poderá ser obtida após replicações deste estudo, preferencialmente, feitas avaliando-se o mesmo tipo de serviço. Isso representa uma potencial fonte para pesquisas futuras. Outra possibilidade seria a replicação do estudo empregando outros serviços terceirizados de manutenção predial, a fim de verificar se o modelo adaptado é capaz de permitir uma boa avaliação da qualidade também deles.

A principal limitação do estudo, pois, consiste em não ser possível generalizar os resultados, mas apenas obter um indício de que os 41 indicadores identificados podem permitir a avaliação da qualidade do serviço terceirizado de manutenção predial aqui identificado como "Serviço de Reparos".

\section{Referências}

ASSOCIAÇÃO BRASILEIRA DE CIMENTO PORTLAND - ABCP. Norma comentada de desempenho NBR 15.575. São Paulo, 2013. Disponível em: <http://www.abcp.org.br/comunidades/ parede_concreto/Coletanea\%20de\%20Ativos/assets/ downloads/2-Normalizacao/04\%20-\%20Norma\%20 Comentada.pdf $>$.

BAYRAKTAROGLU, G. Testing the superiority and dimensionality of Servqual vs. Servperf in higher education. Quality Management Journal, v. 17, n. 1, p. 47-59, 2010.

BEZERRA, J. E. A.; TUBINO, D. F. A manutenção de condomínios em edifícios, TPM, Terceirização e o JIT/ TQC. In: ENCONTRO NACIONAL DE ENGENHARIA DE PRODUÇÃO, 20., 2000, São Paulo. Anais...

BIDO, D. S. et al. Examinando a relação entre aprendizagem individual, grupal e organizacional em uma instituição financeira. In: ENCONTRO NACIONAL DOS PROGRAMAS DE PÓS-GRADUAÇÃO EM ADMINISTRAÇÃO, 32., 2008, Rio de Janeiro. Anais...

BRADY, M. K.; CRONIN JUNIOR, J. J. Some new thoughts on conceptualizing perceived service quality: a hierarchical approach. Journal of Marketing, v. 65, n. 3, p. 34-49, 2001.

BRASIL. Lei no 8.666, de 21 de junho de 1993. Estabelece normas gerais sobre licitações e contratos administrativos pertinentes a obras, serviços (inclusive de publicidade), 
compras, alienações e locações no âmbito dos Poderes da União, dos Estados, do Distrito Federal e dos Municípios. Diário Oficial da União, Poder Executivo, Brasília, DF, 22 jun. 1993. Disponível em: <http://www.planalto. gov.br/ccivil_03/leis/L8666cons.htm>. Acesso em: 17 maio 2009.

BRASIL. Lei n ${ }^{\circ} 10.520$, de 17 de julho de 2002. Institui, no âmbito da União, Estados, Distrito Federal e Municípios, nos termos do art. 37, inciso XXI, da Constituição Federal, modalidade de licitação denominada pregão, para aquisição de bens e serviços comuns, e dá outras providências. Diário Oficial da União, Poder Executivo, Brasília, DF, 18 jul. 2002. Disponível em: <http://www. planalto.gov.br/ccivil_03/leis/2002/L10520.htm>. Acesso em: 12 abr. 2009.

BRESSER PEREIRA, L. C. Do estado patrimonial ao gerencial. In: SACHS, I.; WILHEIM, J.; PINHEIRO, P. S. (Orgs.). Brasil: um século de transformações. São Paulo: Companhia das Letras, 2001. p. 222-259.

BUCHNER, A. et al. G*Power version 3.0.10. Kiel, 2008. Disponível em: <http://www.psycho.uni-duesseldorf. de/aap/projects/gpower/>. Acesso em: 28 nov. 2008.

CARO, L. M.; GARCÍA, J. A. M. Developing a multidimensional and hierarchical service quality model for the travel agency industry. Tourism Management, v. 29, n. 4, p. 706-720, 2008. http://dx.doi.org/10.1016/j. tourman.2007.07.014

CHAHAL, H.; KUMARI, N. Development of multidimensional scale for healthcare service quality (HCSQ) in Indian context. Journal of Indian Business Research, v. 2, n. 4, p. 230-255, 2010. http://dx.doi. org/10.1108/17554191011084157

CRONIN JUNIOR, J. J.; TAYLOR, S. A. Measuring service quality: a reexamination and extension. Journal of Marketing, v. 56, n. 3, p. 55-68, 1992. http://dx.doi. org/10.2307/1252296

DABHOLKAR, P.; THORPE, D. I.; RENTZ, J. Q. A measure of service quality for retail stores. Journal of the Academy of Marketing Science, v. 24, n. 1, p. 3-16, 1996. http://dx.doi.org/10.1007/BF02893933

FIGUEIREDO, F. F. de; GRAVA, J. W. A economia dos empreendimentos built-to-suit. In: CONGRESSO BRASILEIRO DE ENGENHARIA DE AVALIAÇÕES E PERÍCIAS, 15., 2007, Salvador. Anais... Disponível em: <http://www.mrcl.com.br/xivcobreap/tt39.pdf>.

FRANCESCHINI, F. et al. Um modelo para a terceirização. Revista HSM Management, v. 1, n. 42, p. 74-80, 2004.

FREITAS, A. L. P.; BOLSANELLO, F. M. C.; VIANA, N. R. N. G. Avaliação da qualidade de serviços de uma biblioteca universitária: um estudo de caso utilizando o modelo Servqual. Ciência da Informação, v. 37, n. 3, p. 88-102, 2008. Disponível em: <http://www.scielo. br/pdf/ci/v37n3/v37n3a07.pdf>.

GRÖNROOS, C. Marketing: gerenciamento e serviços. Rio de Janeiro: Campus, 1995.

GUMMESSON, E. Marketing de relacionamento total: gerenciamento de marketing, estratégia de relacionamento e abordagens de CRM para a economia de rede. Porto Alegre: Bookman, 2005. PMid:15623807

HAIR JUNIOR, J. F. et al. Análise multivariada da dados. Porto Alegre: Bookman, 2005.
HASSANAIN, M. A.; AL-SAADI, S. A framework model for outsourcing asset management services. Facilities Journal, v. 23, n. 1-2, p. 73-81, 2005. http://dx.doi. org/10.1108/02632770510575910

HOFFMAN, K. D. Marketing de serviços. In: CZINKOTA, M. R. et al. Marketing: as melhores práticas. Porto Alegre: Bookman, 2001.

JAIN, S. K.; GUPTA, G. Measuring service quality: SERVQUAL vs. SERVPERF scales. Vikalpa, v. 29, n. 2, p. 25-37, 2004.

JENSEN, A. et al. The added value of FM: different research perspectives. In: EURO FACILITY MANAGEMENT RESEARCH SYMPOSIUM, 9., 2010, Madrid.

KARMAN, J. Manual de manutenção hospitalar. São Paulo: Pini, 1997.

LINDHOLM, A. L.; NENONEN, S. A conceptual framework of CREAM performance measurement tools. Journal of Corporate Real Estate, v. 8, n. 3, p. 108-119, 2006. http://dx.doi.org/10.1108/14630010610711739

LOPES, E. L.; HERNANDEZ, J. M. C.; NOHARA, J. J. Escalas concorrentes para a mensuração da qualidade percebida: uma comparação entre a Servqual e a RSQ. Revista de Administração de Empresas, v. 49, n. 4, p. 401-416, 2009. http://dx.doi.org/10.1590/ S0034-75902009000400004

LOVELOCK, C.; WRIGHT, L. Serviços: marketing e gestão. São Paulo: Saraiva, 2001.

LU, Y.; ZHANG, L.; WANG, B. A multidimensional and hierarchical model of mobile service quality. Electronic Commerce Research and Applications, v. 8, n. 5, p. 228-240, 2009. http://dx.doi.org/10.1016/j. elerap.2009.04.002

MACEDO, C. M. A estratégia da terceirização de processos de negócios no gerenciamento de facilidades. 2005. Monografia (Especialista em Gerenciamento de Facilidades) - Escola Politécnica da Universidade de São Paulo, São Paulo, 2005.

MIGUEL, P. A. C.; SALOMI, G. G. E. Uma revisão dos modelos para medição da qualidade em serviços. Revista Produção, v. 14, n. 1, p. 12-30, 2004.

MARCOULIDES, G. A.; CHIN, W. W.; SAUNDERS, C. A critical look at Partial Least Squares Modeling. MIS Quarterly, v. 33, n. 1, p. 171-175, 2009.

MIRSHAWKA, V. Manutenção preditiva: caminho para zero defeitos. São Paulo: Makron; McGraw-Hill, 1991.

MONCZKA, R. M. Outsourcing strategically for sustainable competitive advantage. Tempe: CAPS Research, 2005.

MORSE, J. M. Designing funded qualitative research. In: DENZIN, N. K.; LINCOLN, Y. S. Handbook of qualitative research. Tousand Oaks: Sage Publications, 1994. p. 220-235. (cap. 13).

PARASURAMAN, A.; ZEITHAML, V. A.; BERRY, L. L. A conceptual model of service quality and its implications for future research. Journal of Marketing, v. 49, n. 4, p. 41-50, 1985. http://dx.doi.org/10.2307/1251430

PARASURAMAN, A.; ZEITHAML, V. A.; BERRY, L. L. SERVQUAL: a multiple-item scale for measuring consumer perceptions of service quality. Journal of Retailing, v. 64, n. 1, p. 12-40, 1988. 
RASILA, H. M.; GERSBERG, N. F. Service Quality in outsourced facility maintenance services. Journal of Corporate Real Estate, v. 9, n. 1, p. 39-49, 2007. http:// dx.doi.org/10.1108/14630010710742473

REZENDE, W. Terceirização: a integração acabou? Revista de Administração de Empresas, v. 37, n. 4, p. 6-15, 1997. http://dx.doi.org/10.1590/ S0034-75901997000400002

RUST, R. T.; OLIVER, R. L. Service Quality: new directions in theory and practice. Thousand Oaks: SAGE Publication, 1994. PMCid:PMC186279

SALOMI, G. G. E.; MIGUEL, P. A. C.; ABACKERLI, A. J. SERVQUAL $\times$ SERVPERF: comparação entre instrumentos para avaliação da qualidade de serviços internos. Gestão \& Produção, v. 12, n. 2, p. 279-293, 2005. http://dx.doi.org/10.1590/ S0104-530X2005000200011

SAPRI, M.; PITT, M. Performance measurement in facilities management: state of knowledge. In: ANNUAL ARCOM CONFERENCE, 21., 2005, London. Disponível em: <http://www.arcom.ac.uk/publications/procs/ar20050431-0440_Sapri_and_Pitt.pdf>.

SOARES, J. C. V.; SCHEFFLER, A. Avaliação da qualidade de serviços através da aplicação da Escala SERVQUAL numa agência bancária de Ijuí RS. In: SEMINÁRIOS EM ADMINISTRAÇÃO, 8., 2005, São Paulo. Anais... SZIGETI, F.; DAVIS, G. Performance based building: conceptual framework. Rotterdam: CIB Development Foundation, 2005. (PeBBu Final Report). Disponível em: <http://www.pebbu.nl/resources/allreports/ downloads/04_framework_final.pdf $>$.

THEN, D. S. S. A proactive property management model that integrates real state provision and facilities service management. International Journal of Strategic Property Management, v. 9, n. 1, p. 33-42, 2005.

YIN, R. K. Estudo de caso: planejamento e métodos. Porto Alegre: Bookman, 2005.

ZEITHAML, V. A.; BITNER, M. J. Marketing de serviços: a empresa com foco no cliente. Porto Alegre: Bookman, 2003.

ZWICKER, R.; SOUZA, C. A.; BIDO, D. S. Uma revisão do modelo do grau de informatização de empresas: novas propostas de estimação e modelagem usando PLS (partial least squares). In: ENCONTRO DA ASSOCIAÇÃO NACIONAL DE PÓS-GRADUAÇÃO E PESQUISA EM ADMINISTRAÇÃO, 32., 2008, Rio de Janeiro. Anais eletrônicos... 